\title{
SELECTION AND JUSTIFICATION OF POTATO INTER ROW TILLAGE SYSTEMS BASED ON DEVELOPMENT OF DYNAMIC MODEL OF HEAT AND MOISTURE TRANSFER BETWEEN SOIL LAYERS
}

\author{
Andrei Kalinin, Valintina Kalinina, Igor Teplinsky, Vycheslav Ruzhev \\ Saint-Petersburg State Agrarian University, Russia \\ andrkalinin@yandex.ru,val.kalinina@gmail.com, agro@spbgau.ru,ruzhev_va@mail.ru
}

\begin{abstract}
Ambient temperature, frequency and intensity of precipitation in natural conditions are random processes that cannot be controlled. Therefore, it will be possible to regulate the moisture content on the roots spreading zone only due to the formation by the tillage machines and their working bodies of a certain soil structure in the layer being treated, on which the heat exchange between soil horizons will depend. To select and justify the type of tillage machines and their working bodies, it is proposed to develop a soil condition model that describes the moisture content level of the root zone for certain soil and weather conditions, presented in the form of a dynamic system. To develop a common model of the soil state based on the parameters of heat and moisture transfer, elementary layers soil state models were completed for the each layer to a depth until $90 \mathrm{~cm}$. The conducted field experimental studies made it possible to obtain reliable information on the state of the soil in terms of its moisture and temperature in different layers of the soil horizon, depending on the use of different types of interrow cultivators in the intensive technology of potato growing in the same soil and climatic conditions on the same field. Statistical processing of the results of experimental studies made it possible to obtain a reliable estimate of the soil temperature and soil moisture content processes. Based on the mathematical processing of the experimental data, elementary model operators were obtained and their validity was verified by regression analysis methods. Due to using these models, it is possible to make a prognostic assessment of the soil moisture parameter in the underlying layers of the soil horizon based on an assessment of the degree of moistening topsoil layer. It is also possible to predict the level of moisture supply of plants depending on the type of tillage and its depth.
\end{abstract}

Keywords: soil, tillage system, moisture transfer, heat transfer.

\section{Introduction}

Numerous studies have shown that the level of soil moisture content in the root-spreading zone largely depends on the outside air temperature, the temperature gradient between different soil horizons $[1 ; 2]$ and the level of precipitation during the growing season [3]. Outside temperature, frequency and intensity of precipitation in natural conditions are random processes that cannot be controlled [4-6]. Therefore, to control the level of the moisture in the root-spreading zone, it is proposed to use various types of tillage machines, which can create the required ratio between large pores and capillaries inside the tilled soil [7;8].

To select and justify the type of interrow tillage machines that are used for ridge forming in the potato growing technology, it was proposed to consider a soil state model that describes the moisture supply level of the root-spreading zone for certain soil and weather conditions depending on the intensity of heat transfer between soil layers [9]. To considerationthe general model of the soil state by parameters of heat and moisture transfer, elementary soil state models were compiled for the $i$-th 10 and $30 \mathrm{~cm}$ thick soil layer to a depth of $70 \mathrm{~cm}$. It is proposed that operators of elementary models be obtained by statistical identification methods of random processes of changes in the moisture content $W_{i}$ and soil temperature $T_{i}$ of upper and lower boundaries of the elementary soil horizon, which were continuously recorded throughout the entire potato growing period. Using these models, it is possible to make a prognostic assessment of the moisture content in the root-spreading zone of the soil based on an assessment of the precipitation level on the field surface depending on the type of interrow tillage machines in the potato technology.

\section{Materialsandmethods}

Analysis of the science research results shows that during potato growing period the level of moisture content in the root-spreading zone largely depends on the outside air temperature, the temperature gradient between soil horizons and the level of precipitation during the growing season [10]. Ambient temperature, the frequency and intensity of precipitation in natural conditions are random processes that cannot be controlled. Therefore, it will be possible to control the soil 
moisture level in the root-spreading zone due to the formation of a certain soil structure in the treated layer by tillage machines, which will determine the heat transfer between soil horizons [11].

Thus, the general model of the soil state, which describes the level of moisture supply for the rootspreading zone for certain soil conditions, can be presented as a dynamic system consisting of several elementary models characterizing the state of the corresponding $i$-th soil horizons (Fig. 1). Inputs of this model are random processes of the outdoor temperature $T_{o}(t)$ and precipitation level $P_{o}(t)$. The topsoil, located on the air-soil border, has some moisture content $W_{B}(t)$. Under the influence of external temperature, as well as the ability of the soil surface to absorb solar radiation, the temperature regime is formed at the surface of the upper soil horizon $T_{B}(t)$. Assume that the thickness of the elementary soil layer equal to the spacing of the sensors in the measuring probe, recording the moisture and temperature of the corresponding soil horizons. Depending on the level of thermal conductivity of the upper soil layer, its lower boundary will have a temperature $T_{1}(t)$. Under the effect of moisture movement through the soil capillaries caused by the temperature gradient, the initial moisture content $W_{B}(t)$ at the upper boundary of the elementary layer is converted to moisture $W_{1}(t)$ at its lower boundary. The processes $T_{1}(t)$ and $W_{1}(t)$, acting on the next lower layer are transformed into processes $T_{2}(t)$ and $W_{2}(t)$, which characterize these parameters of the soil state at the lower boundary of the underlying layer. Thus, there is a change in temperature and soil moisture in the each $i$-th layers. The soil moisture level in each elementary $i$-th layer corresponds to the total moisture reserves in the root-spreading zone $V_{W}$, which determine the general conditions for the growth and development of the potato. Therefore, as an output indicator of the soil state model, we take the process of changing moisture reserves in the root-spreading zone $V_{W}(t)$. As a control vector of the soil state model, we take the degree of the soil crumbling index $K_{p}$, which determines the thermal conductivity of the treated layer, which is largely determined by the ratio of large pores and capillary channels.

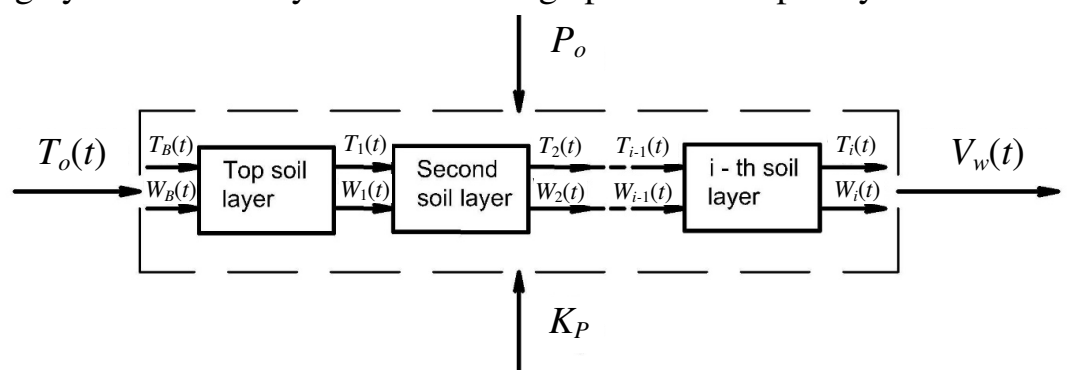

Fig. 1. Model of the soil state of the root-spreading zone

Using these models, it is possible to make a prognostic assessment of the soil wetness parameter in the underlying layers of the soil horizon, based on an assessment of the degree of soil wetness on the field surface [12]. Based on the data of thelevel of precipitation and topsoil wetness, it is possible to predict the level of moisture supply of the plant root system depending on the type of tillage machine and working depth [13].

Due to the fact that the general model of the soil state consists of several elementary models corresponding to soil horizons, we consider a particular model for the $i$-th layer (Fig. 2). The inputs of the elementary model of the $i$-th soil layer are random processes of the temperature $T_{i-1}(t)$ and humidity $W_{i-1}(t)$ at the upper boundary of this soil horizon. The outputs of this model are the random processes of the temperature $T_{i}(t)$ and humidity $W_{i}(t)$ at the lower boundary of the current soil horizon. Preliminary theoretical studies of moisture movement inside a capillary an isothermal system showed that the soil wetness $W_{i}(t)$ depends on the temperature difference $q_{i}(t)=T_{i}(t)-T_{i-1}(t)$ and the initial moisture content $W_{i-1}(t)$. At the same time, the random process of precipitation of $P_{O}(t)$ has a significant effect on soil wetness. Control of elementary model is provided by changing of the soil structure $\mathrm{K}_{\mathrm{P}}$ in the considered layer, which is formed by tillage machines [14].

During the experimental studies, two types of inter row cultivators were used as objects for cultivation of potato plantings: GF 400, which till soil byknifes on the rotorand form ridges with rigid hood; and GH 4, which till soil by combination of the rigid and spring tines and form ridges by cage rollers. Thesecultivators created inside the ridges, respectively, a dense small-crumbly and rough crumbly soil structure. 
Empirical operators of elementary models for each layer were obtained on the basis of statistical processing of measurement results with simultaneous registration of input and output processes. To obtain information, experimental equipment using digital systems for measuring, processing and telemetric data transmission was used.

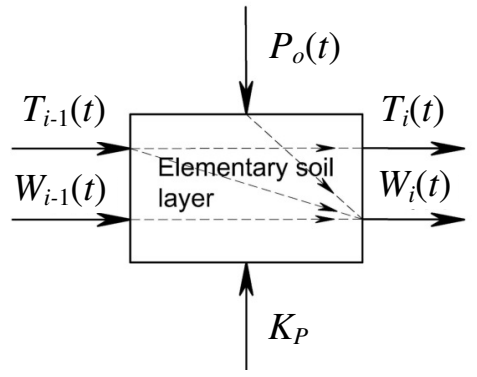

Fig. 2. Model of elementary soil horizon

The weather conditions, as the air temperature and precipitation, were recorded using the Dacom mobile weather station installed on the field. The parameters of the soil state in the root-spreadingzone were recorded - the soil temperature and soil wetness in the various horizons using measuring probes that were installed in the same potato field after the passage of both cultivators mentioned above. The registration of soil wetness was carried out by measuring an indirect indicator - the electromagnetic permeability of the soil located in close proximity to the coil generating electromagnetic waves. A pair of electromagnetic coils (electromagnetic field generator and signal receiver) are placed with a step of $10 \mathrm{~cm}$ inside a plastic probe 1 meter long (Fig. 3). Soil temperature was measured by temperature sensors installed inside the same probe with a step of $30 \mathrm{~cm}$, starting from a depth of $10 \mathrm{~cm}$.

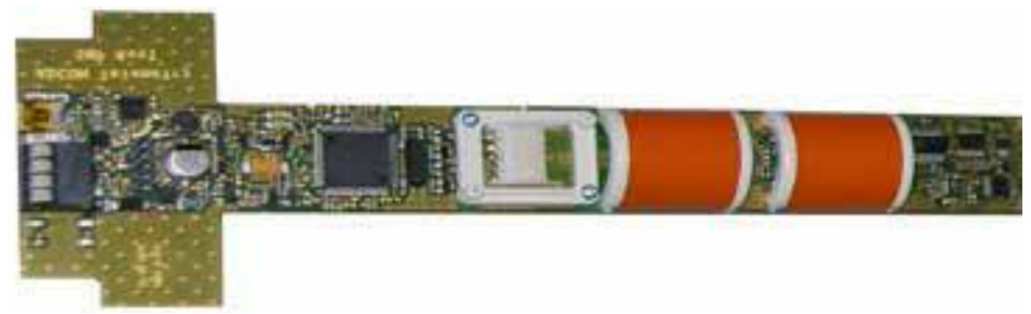

Fig. 3. Section of a soil parameter measuring probe

The measuring probe was mounted vertically in the center of the ridge. Using a wire, the probe was connected to the data collection unit equipped with a GSM modem. The electronic devices and the signal transmitter are powered by a rechargeable battery, which is charged by the solar battery in the daytime. The measuring complex also includes a pluviometer for measuring the amount of precipitation that fell directly at the measuring probe. All data were recorded every 15 minutes. During the operation of the measuring complex, signals from the sensors enter to the collection unit, where they are digitized and stored in the internal memory. Daily collected data were sent via a GSM modem in automatic mode to the cloud storage server, where the database is accumulated. Access to the database is carried out from any personal computer connected to the Internet by entering the login and password on the cloud storage server. After the completion of field studies, all the information obtained for the entire observation period is copied from the database in a table form. Further information processing is carried out by methods of mathematical statistics.

The conducted field experimental studies made it possible to obtain real information about the state of the soil in terms of its wetness and temperature in different layers of the soil horizon, depending on the use of different types of inter-row cultivators during potato growing in the same soil and climatic conditions on the same field. Statistical processing of the results of experimental studies made it possible to estimate the soil condition in the root-spreading zone by the parameters of heat and moisture transfer.

\section{Results and discussion}

As a result of the experimental studies, data were obtained on the input and output random processes of the soil state mode in the form of realizations of the outdoor temperature $T_{o}(t)$ and 
precipitation level $P_{o}(t)$, soil temperature in the zone of tuber formation $T_{1}(t)$ at a depth of $10 \mathrm{~cm}$, the soil temperature in the layer below the arable horizon $T_{2}(t)$ at a depth of $40 \mathrm{~cm}$ and the soil temperature $T_{3}(t)$ in the lower part of the root-spreading zone at a depth of $70 \mathrm{~cm}$. Soil wetness $W_{i}(t)$ was measured in layers from 10 to $90 \mathrm{~cm}$ in increments of $10 \mathrm{~cm}$. Based on the measurements of soil moisture in these layers of the root-spreading zone, the total moisture reserves $V_{W}(t)$ were determined. When performing experimental studies, continuous observations were carried out for 70 days, during which more than 6800 measurements of the interested us parameters of the soil state were made. A large array of obtained data provides significant statistical reliability of the estimates of the studied processes and regression equations describing the relationship between various parameters of the soil state.

In the statistical processing of implementations of input and output processes, their quantitative and qualitative estimates were obtained. Analysis of the statistical characteristics of random processes of the soil model showed that the level of moisture supply to the root system of plants depends on the method of interrow cultivation of the soil. The results of statistical processing served as the basis for conducting a regression analysis of the soil state model formed by various methods of inter-row tillage.

As a result of statistical processing of the results of experimental studies, regression equations and cross-correlation coefficients for each elementary model were obtained that quantitatively determine the degree of their mutual connection.

It was previously indicated that for each of the studied layers of the soil horizon, the temperature regime and the level of moisture supply can be described by elementary models of heat transfer and moisture transfer, respectively. Based on theoretical assumptions about the nature of the action of the phenomenon of moisture transfer inside the soil, we proposed to describe these models with linear regression equations in the form of the expression $Y=a * X+b$.

Table 1 presents the coefficients of the regression equations and the square of the correlation coefficient $\left(R^{2}\right)$ for heat transfer models of soil layers for various methods of inter-row cultivation of planting potatoes: GF 400 and GH-4. These models were built for soil horizons of $0-10 \mathrm{~cm}, 10-40 \mathrm{~cm}$ and $40-70 \mathrm{~cm}$. The calculation of the coefficients of the regression equations for these models was carried out taking into account the time shift of the output process relative to the input due to a certain inertia of the soil during the transfer of thermal energy. For layers of $0-10 \mathrm{~cm}$ and $10-40 \mathrm{~cm}$, this shift is 6 hours, for a layer of $30-70 \mathrm{~cm}-30$ hours.

Table 1

\section{Coefficients of regression equations for heat transfer models of different soil horizons of the root-spreading zone}

\begin{tabular}{|c|c|c|c|}
\hline \multirow{2}{*}{$\begin{array}{c}\text { Regression } \\
\text { Equation Index }\end{array}$} & $0-10 \mathrm{~cm}$ & $10-40 \mathrm{~cm}$ & $40-70 \mathrm{~cm}$ \\
\cline { 2 - 4 } & \multicolumn{3}{|c|}{ GF 400 } \\
\hline$a$ & 0.42 & 0.30 & 0.64 \\
\hline$b$ & 11.81 & 11.80 & 4.87 \\
\hline$R^{2}$ & 0.74 & 0.61 & 0.91 \\
\hline \multicolumn{4}{|c|}{ GH 4 } \\
\hline$b$ & 0.34 & 0.34 & 0.63 \\
\hline$b$ & 12.77 & 10.89 & 4.80 \\
\hline$R^{2}$ & 0.72 & 0.74 & 0.87 \\
\hline
\end{tabular}

An analysis of Table 1 showed that the input and output processes of heat transfer models in the upper and lower soil horizons have high values of cross-correlation coefficients, which indicates a linear relationship between them. Based on these data, it is possible to draw a conclusion and the possibility of predicting the temperature of the soil in various layers with a fairly high degree of reliability, using the obtained equations for heat transfer models.

Table 2 presents the coefficients of the regression equations and the square of the correlation coefficient formoisture transfer models in different horizons of the root-spreading zoneinside the soil layers for various methodsof inter-row cultivation of the planted potatoes: by cultivatorGF 400 and 
tine cultivator GH-4. These elementary models were obtained for each 10-cm layer to a depth of 70 $\mathrm{cm}$.

Table 2

\section{Coefficients of regression equations for moisture transfer models in different horizons of the root-spreading zone}

\begin{tabular}{|c|c|c|c|c|c|c|c|c|}
\hline \multirow{2}{*}{$\begin{array}{c}\text { Regression } \\
\text { Equation Index }\end{array}$} & \multicolumn{8}{|c|}{ Soil horizon } \\
\hline & $10-20$ & $20-30$ & $30-40$ & $40-50$ & $50-60$ & $60-70$ & $70-80$ & $80-90$ \\
\hline \multicolumn{9}{|c|}{ GF 400} \\
\hline$a$ & 0.97 & 1.61 & 1.15 & 0.22 & 0.33 & 0.002 & 0.72 & 1.97 \\
\hline$b$ & 11.89 & 5.50 & 0.31 & 43.45 & 38.07 & 58.00 & 9.41 & -61.2 \\
\hline$R^{2}$ & 0.35 & 0.88 & 0.91 & 0.95 & 0.98 & 0.01 & 0.14 & 0.74 \\
\hline \multicolumn{9}{|c|}{ GH 4} \\
\hline$a$ & 0.95 & 0.90 & 0.97 & 0.72 & 0.34 & 0.27 & -0.03 & 0.33 \\
\hline$b$ & 11.79 & 5.26 & 6.79 & 14.09 & 36.75 & 44.11 & 59.90 & 37.44 \\
\hline$R^{2}$ & 0.57 & 0.68 & 0.98 & 0.99 & 0.99 & 0.91 & 0.01 & 0.47 \\
\hline
\end{tabular}

The analysis of Table 2 showed that the soil structure largely determines the structure of moisture transfer models within the studied soil horizons. For a loose soil structure with a large content of large pores saturated with air, the relationship between the importance process at the upper boundary of the $W_{i-1}(t)$ horizon and the moisture process at its lower boundary $W_{i}(t)$ is rather weak or absent. In denser soil with a tight contact between soil particles moisture transfer models describe the patterns of intrasoil processes to a large degree of adequacy, as evidenced by the high squares of the cross-correlation coefficients for layers located below the depth of processing of tillage tools $(20 \mathrm{~cm}$ and deeper $)$. At a depth of more than $70 \mathrm{~cm}$, there is also a lack of a clear relationship between the input and output processes of moisture transfer models. This is due to the presence of a gravel layer at this depth at the transition of the soil horizon to the parent rock.

a)

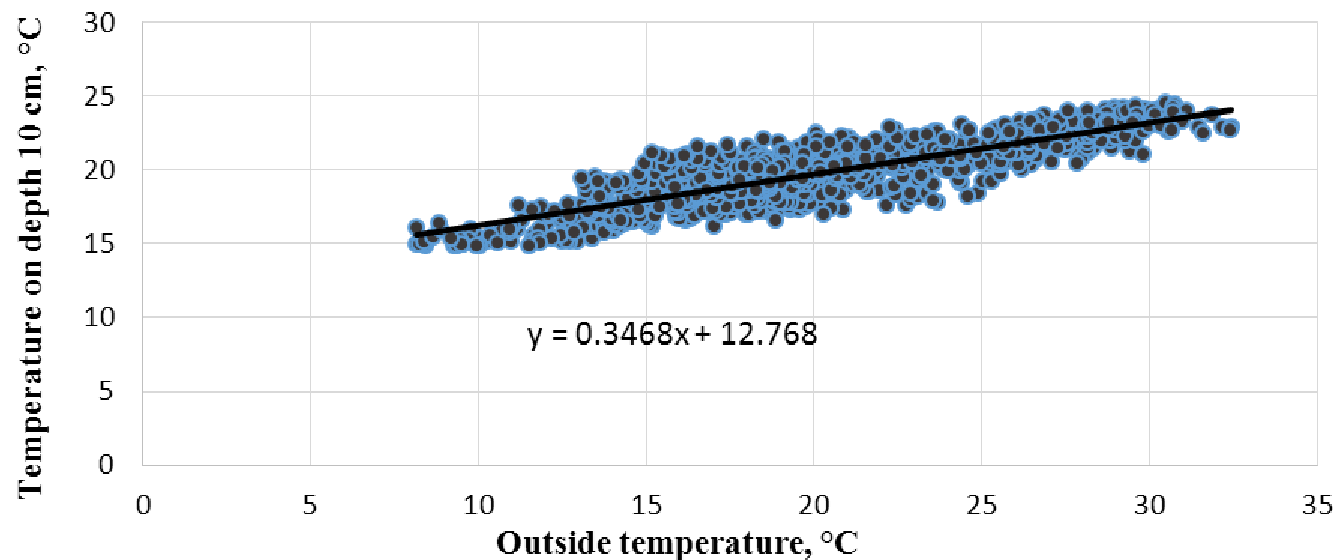

b)

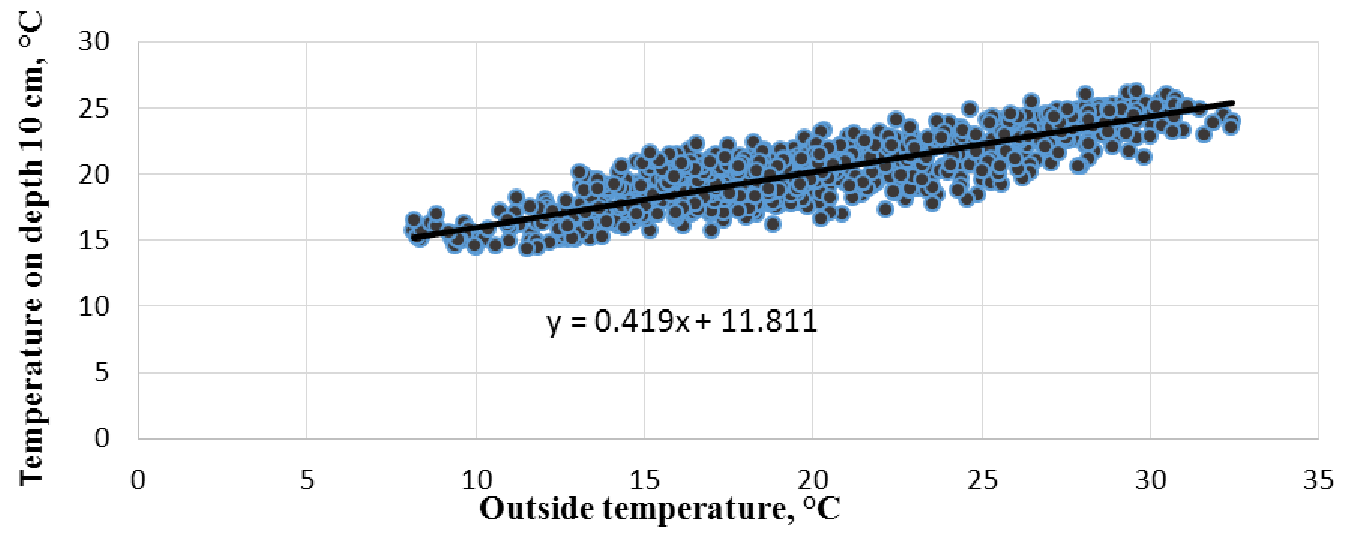

Fig.4. Graphical interpretation of the regression model of heat transfer in the upper soil horizon: a - after application of the cultivator GH 4; b - after applying the cultivator GF 400 
Figure 4 presents a graphical interpretation of the regression model of heat transfer in the upper soil horizon, when using a tine cultivator GH 4 (a) and a GF 400 cultivator (b). The lower correlation coefficient in the heat transfer model for the upper soil layer after passes GH 4 indicates that the loose soil structure inside the ridges with a large amount of air forms a thermally insulating layer, which to a less extent transfers the temperature of the outside air to the lower layers of the soil horizon.

$$
\text { a) }
$$
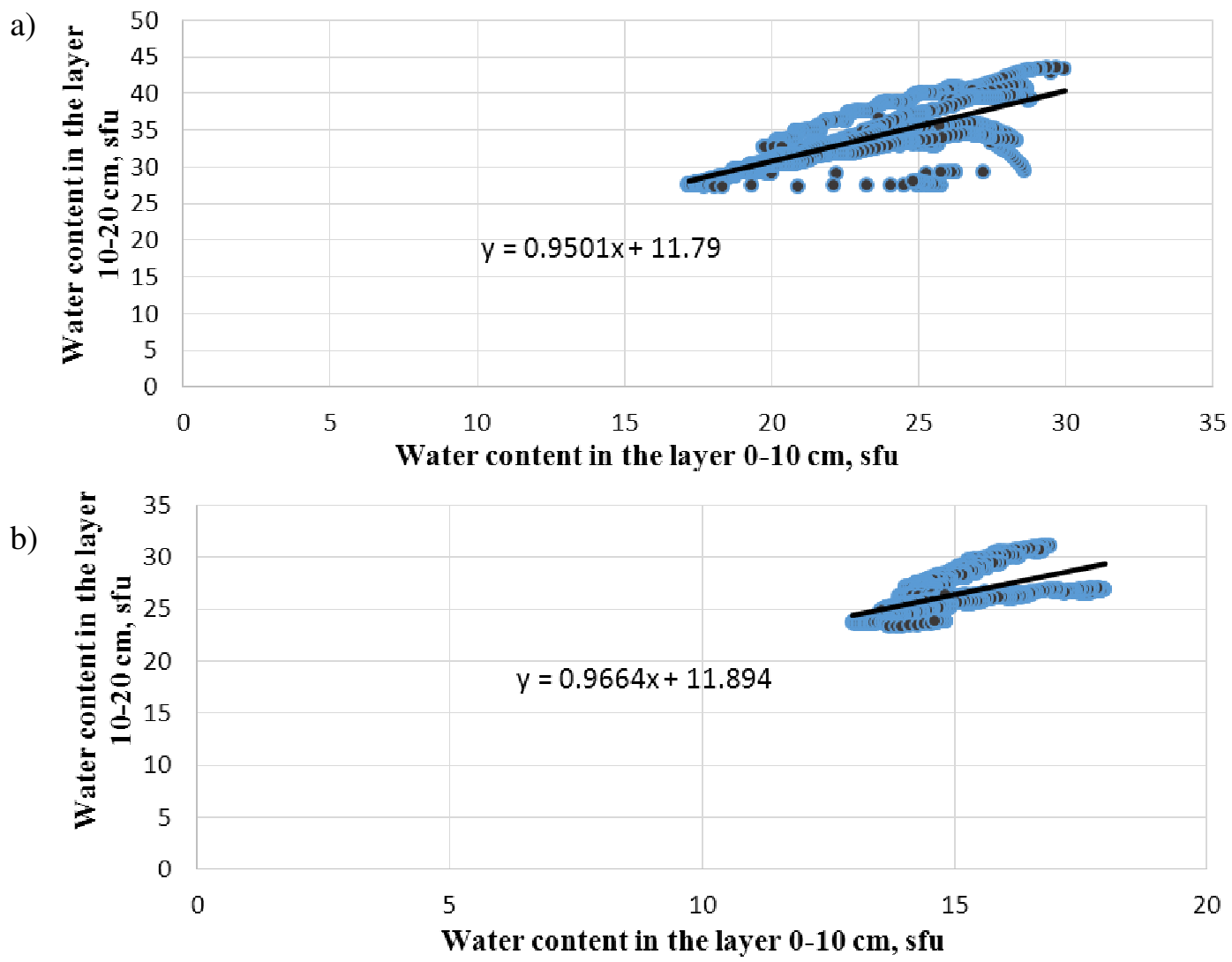

Fig. 5. Graphical interpretation of the regression model of moisture transfer between layers at a depth of 10 and $20 \mathrm{~cm}$ : a - after application of the GH 4 cultivator; $b$ - after applying the cultivator GF 400

Figure 5 presents a graphical interpretation of the regression model of moisture transfer in the upper soil horizon, when using a cultivator GH 4 (a) and a GF 400 cultivator (b).

It should also be noted that the smooth surface of the ridges formed by the GF 400 cultivator significantly reduces the flow of moisture into their upper part. Therefore, a low correlation coefficient is noted for the moisture transfer model in the 10-20 cm layer.

Due to the fact that the level of precipitation and the use of moisture reserves by plants do not compensate for the outflow of moisture from the lower layers of the root-spreading zone to the lower layers of the soil profile, some coefficients of the regression equations for the moisture transfer model in the $80-90 \mathrm{~cm}$ layer take negative values.

\section{Conclusions}

1. Based on the analysis of the results of the study, we can conclude that the regression models of moisture transfer for soil layers with a predominance of capillary channels have a high degree of identity when they are described by linear equations. Using these models, it is possible to make a prognostic assessment of the soil moisture parameter in the underlying layers of the soil horizon based on measurements of this process at the topsoil layer. In this case, the layer thickness, in which a linear relationship between input and output processes is observed, can reach $50-60 \mathrm{~cm}$. Based on the dynamics of changes in soil moisture in the upper soil horizon, it is possible to predict the level of moisture supply of plants depending on the type of tillage machine and working depth. 
2. Thus, analysis of the results of processing statistical data of processes describing the soil state model of the root layer showed that tillage with a cultivator with passive working bodies [15], after which a relatively coarse soil structure of ridges with a high content of pores saturated with air remains to the formation of a thermally insulating layer on the profiled surface of the soil.The use of loosening tines provides a more uniform distribution of moisture in the root spreading zone, as evidenced by the high average values of the coefficients of cross-correlation of moisture transfer processes between soil horizons. The presence ofcoarse soil structure in such layers reduces the outflow of moisture to the underlying layers of the soil horizon under the influence of the phenomenon of heat and moisture transferring and ensures its uniform distribution throughout the root-spreading zone without the formation of desiccation and waterlogging, as well as an increase in the total moisture reserves available for plant roots.

3. Further research is planned to be directed to improving the ripper tines of interrow cultivators with passive working bodies, the use of which will allow to obtain predictable heat and moisture conductivity of the treated layer, which affects the level of wetness of soil zones where is placed the potato root system.

\section{References}

[1] Hopmans J.W., DaneJ.H. Combined effect of hysteresis and temperature on soil-water movement Journal of HydrologyVolume 83, Issues 1-2, 15 January 1986, pp. 161-171.

[2] Gurr C. G., Marshall T. J., Hutton J. T. Movement of water in soil due to a temperature gradient. Soil Science: November 1952 - Volume 74 - Issue 5, pp. 335-346.

[3] Qiao X., Ma S., Pan G., etc. Effects of Temperature Change on the Soil Water Characteristic Curve and a Prediction Model for the Mu Us Bottomland, Northern China. Water 2019, 11(6), 1235

[4] Hopmans J., Dane J.H. Effect of temperature-dependent hydraulic properties on soil water movement. Soil Sci. Soc. Am. J. 1985, 49, pp. 51-58.

[5] Mc. Michael B.C., Burke J.J. Soil temperature and root growth. Hort Science. 1998;33 (6), pp. 947-951.

[6] Noborio K., Mclanes K.J. Thermal conductivity of salt- affected soils. Soil science society of AmericaJournal. 1993;57(2), pp. 329-334.

[7] Abu-Hamdah N.H., Reeder R.C. Soil thermal conductivity affects of density, moisture, salt concentration and organic matter. Soil science society of America Journal, 2000; 64(4), pp. 12851290

[8] Abu-Hamdah N.H. Thermal properties of soils as affected by density and water content. Biosystemsengineering. 2003, 86(1), pp. 97-102.

[9] Ochsnor T.E., Horton R., Ren T. A new perspective on soil thermal properties. Soil science societyof American journal. 2001;65(6), pp. 1641-1647.

[10]Elias E.A., Cichota R., Torraiani H.H., et al. Analytical soil temperature model: correction for temporal variation of daily amplitude. Soil science society of America Journal. 2004;68(3), pp. 784-788.

[11] Daliya R., Ingwersen J., Streek T. The effect of mulching and tillage on the water and temperature regimes of a loess soil. Experimental finings and modeling. Soil and tillage research. 2007;96(12), pp. 52-63.

[12] Terefe T., Mariscal Sancho I., Peregrima F., et al. Influence of heating on various properties of sic Mediterranean soils. A laboratory study. Geoderma. 2008;143(3-4), pp. 273-280.

[13] Sándor R., Fodor N. Stimulation of soil temperature dynamics with models using different concepts. The scientific world journal. 2012;200, pp. 12-20.

[14] Kalinin A., Teplinsky I., Ustroev. A. Substantiation of tillage methods aimed at rational usage of water resources. Engineering for rural development. 17th International Scientific Conference. 2018. pp. 392-399.

[15] Kalinin A. B., Teplinsky I. Z., Ustroev A. A., etc. Selection and substantiation of cultivator adjustment parameters for differential soil treatment on potato based on the rheology state of soil horizons. III International Conference "Cognitive Robotics". IOP Publishing. IOP Conf. Series: Materials Science and Engineering 516 (2019) 012025. 